Syntax Literate: Jurnal Ilmiah Indonesia p-ISSN: 2541-0849

e-ISSN: 2548-1398

Vol. 6, No. 5, Mei 2021

\title{
METODE MNEMONIK DALAM LAGU SEBAGAI ALTERNATIF PEMBELAJARAN BAHASA JEPANG DI INDONESIA
}

\section{Susanti Aror}

Universitas Negeri Manado, Indonesia

Email: susantiaror@unima.ac.id

\begin{abstract}
Japanese language education (Nihongo Kyoiku) 日本語 教育as a foreign language, namely "Japanese language education which is held for learners who do not speak Japanese as their mother tongue". In its implementation, Japanese language education is seen as a whole system that includes; curriculum, materials, teaching methodology, teaching media, learner teaching, evaluation, and facilities. The use of the mnemonic method is based on the assumption that the human brain consists of two types of memory, namely "natural" and "artificial / arificial" memory. Natural memory is a gift from birth and is used in everyday life, while artificial memory is built by learning and can be trained using mnemonic methods. In addition to being able to apply this mnemonic method by connecting meanings through a series of stories to remember information, also commonly applied using image associations, rhymes, rhymes, acronyms or acrostics. The results showed that learning Japanese using the mnemonic method as a brain memory aid. Japanese learning can be 'registered' to the brain with a meaningful or meaningful memory because it is accompanied by the use of a medium that is a song. The mnemonic method used is the association technique and the word marker. In a natural situation in practice, there is a tendency to have a significant influence on the process of achieving language learning. With repeated application on various occasions including learning songs which in addition to being repeated repeatedly followed by kinesthetic movements and starting at a young age, it produces "memory" memories that are proven to have long-term memory endurance. acronym or acrostic. The results showed that learning Japanese using the mnemonic method as a brain memory aid. Japanese learning can be 'registered' to the brain with a meaningful or meaningful memory because it is accompanied by the use of a medium that is a song. The mnemonic method used is the association technique and the word marker. In a natural situation in practice, there is a tendency to have a significant influence on the process of achieving language learning. With repeated application on various occasions including learning songs which in addition to being repeated repeatedly followed by kinesthetic movements and starting at a young age, it produces "memory" memories that are proven to have long-term memory endurance.,
\end{abstract}

Keywords: method, mnemonic song, Japanese

\begin{tabular}{ll}
\hline How to cite: & Aror, Susanti (2021) Metode Mnemonik Dalam Lagu Sebagai Alternatif Pembelajaran Bahasa Jepang \\
& di Indonesia. Syntax Literate. 6(5). http://dx.doi.org/10.36418/syntax-literate.v6i5. 2741 \\
E-ISSN: & $2548-1398$ \\
Published by: & Ridwan Institute
\end{tabular}




\begin{abstract}
Abstrak
Pendidikan bahasa Jepang (Nihongo Kyoiku) 日本語教育sebagai bahasa asing yaitu "pendidikan bahasa Jepang yang diselenggarakan bagi pembelajar yang tidak berbahasa Jepang sebagai bahasa ibunya”. Dalam pelaksanaanya pendidikan Bahasa Jepang dipandang sebagai suatu sistem keseluruhan yang mencakup; kurikulum, materi, metodologi pengajaran, media pengajaran, pengajar pemelajar, evaluasi, dan fasilitas. Penggunaaan metode mnemonik berdasarkan asumsi bahwa otak manusia terdiri dari dua jenis ingatan yaitu "alami/natural" dan ingatan "buatan/arificial". Ingatan alami merupakan bakat sejak lahir dan digunakan dalam kehidupan seharihari, sedangkan ingatan buatan dibangun dengan cara belajar dan bisa dilatih dengan menggunakan metode mnemonik. Metode mnemonik ini selain dapat di aplikasikan dengan menghubungkan makna melalui rangkaian cerita untuk mengingat sebuah informasi, juga umumnya diaplikasikan dengan menggunakan asosiasi gambar, rima, sajak, akronim atau akrostik. Hasil penelitian menunjukan bahwa pembelajaran bahasa Jepang dengan metode mnemonik sebagai alat bantu ingatan otak. Pembelajaran Bahasa Jepang dapat 'didaftarkan' ke otak dengan sebuah ingatan yang berarti atau bermakna karena disertai dengan penggunaan sebuah media yang lagu. Metode mnemonik yang digunakan dengan teknik asosiasi dan kata penanda. Situasi yang alami dalam berlatih, ada kecenderungan mempunyai pengaruh yang signifikan dalam proses pencapaian belajar bahasa. Dengan penerapan berulangulang pada berbagai kesempatan termasuk pembelajaran Lagu yang selain berulangulang diikuti dengan gerakan kinestetik dan dimulai pada usia muda menghasilkan ingatan "memori" yang teruji memiliki daya tahan mengingat dalam jangka waktu yang lama.
\end{abstract}

Kata Kunci: metode; mnemonik lagu; bahasa Jepang

\title{
Pendahuluan
}

Peserta didik adalah manusia unik dan memiliki karakteristik khas yang sangat personal. Mereka adalah pribadi yang membutuhkan, kenyamanan, keamanan, dan kehangatan dalam proses pembelajaran. Peserta didik membutuhkan suasana yang nyaman agar mereka dapat melaksanakan seluruh aktivitasnya dengan joyful dan meaningful. Jika mereka belajar dalam keadaan tertekan, baik secara psikologis maupun fisik, maka hasil pembelajaran dapat dipastikan tidak akan efektif dan efisien. Oleh karena itu, pendidikan yang memperhatikan nilai kemanusiaan yang berisi kehangatan, kenyamanan, dan estetik perlu diterapkan dan dikembangkan berdampingan dengan pembelajaran berbasis kompetensi.

Tidak dipungkiri bahwa sebagian peserta didik belajar dengan terpaksa dan cenderung formalitas, 2 termasuk di dalamnya belajar bahasa. Lebih ironis lagi, sebagian besar peserta didik memandang pelajaran bahasa asing (termasuk Bahasa Jepang) sebagai momok. Jika demikian halnya, maka dapat dipastikan bahwa dalam proses pembelajaran terdapat segudang masalah di antaranya adalah: 1) rendahnya motivasi siswa; 2) rendahnya partisipasi peserta didik dalam proses pembelajaran; 3) tingginya tuntutan pencapaian komptensi; 4) kurangnya fasilitas pembelajaran, dan lainnya. Problem solving yang tidak ringan ini menjadi beban yang juga harus dipikul oleh guru. 
(Krashen, 1984) dikutip oleh (Huda, 2017) menemukan bahwa hubungan antara jumlah waktu mengikuti pelajaran bahasa asing dengan kemampuan berbicara dalam bahasa asing dari kedua lingkungan bahasa yang berbeda (lingkungan informal dan lingkungan formal) terbukti masing-masing mempengaruhi kemampuan berbahasa asing seseorang. Lingkungan bahasa informal memberikan masukan untuk pemerolehan sedangkan, lingkungan formal memberikan masukan untuk monitor (Krashen, 1984). Artinya, dalam lingkungan alamiah, orang-orang dewasa penutur asli bahasa yang sedang dipelajari dapat berperan dalam membantu para pelajar dengan memberikan balikan atas tuturan pembelajar.

Dalam kehidupan masyarakat, nyanyian sangat berpengaruh terhadap jiwa manusia. Pada masa pendudukan Jepang, nyanyian telah menjadi alat propaganda yang cukup mujarab. Lagu memiliki peranan yang penting. Lagu dapat menyebabkan seseorang merasa senang, sedih, marah, dan juga bersemangat. Kesatuan dari lirik dan kombinasi nada yang baik menciptakan sebuah harmoni yang sangat nyaman untuk didengar.Lagu sebagai sarana ekpresi diri untuk menyampaikan pesan berupa nilai-nilai kehidupan bersifat universal atau lintas budaya. Hal ini pun dapat dilihat dari kuatnya pengaruh Lagu-Lagu dari suatu negara kolonial, yang pernah menjajah suatu bangsa tertancap kuat di benak warga jajahan tersebut, bahkan diwariskan turun-temurun untuk dinyanyikan dalam peristiwa-peristiwa tertentu.

Nyanyian sebagai sarana ekspresi diri untuk menyampaikan pesan berupa nilainilai kehidupan bersifat universal dan dapat diterima oleh orang lain dalam konteks lintas budaya sekalipun, apalagi nyanyian tersebut memberi kesan yang sangat menyenangkan. Sebagai contoh, yang terjadi pada masa kolonial, di mana ide-ide dalam rupa syair nyanyian, yang disampaikan oleh negara kolonial melalui nyanyian syair sangat kuat tertancap dalam hati masyarakat jajahannya, bahkan terwaris terus menerus pada temurunnya, karena kesan yang diakibatkan oleh nyanyian tersebut. Demikian halnya dengan ide dalam syair satu nyanyian yang disampaikan bangsa Jepang pada masyarakat Minahasa, di masa penjajahannya di Minahasa telah tertancap kuat dalam hati dan ingatan orang Minahasa waktu itu. Orang Minahasa waktu itu semakin kuat mengingat nyanyian-nyanyian Jepang tersebut, karena mereka telah mempelajarinya. Faktor pendorong yang kuat untuk mempelajari nyanyian-nyanyian tersebut adalah karena orang Minahasa suka akan alunan nyanyiannya. Selain itu, sejak masa lalu orang Minahasa sudah dikenal sebagai masyarakat yang suka akan nyanyian dan suka bernyanyi, sehingga masyarakat Minahasa disebut sebagai singing society (Rumengan, 2007).

Observasi awal yang dilakukan peneliti terhadap beberapa informan yang pernah mengalami masa pendudukan Jepang di Minahasa mendapat reaksi yang cukup antusias terhadap nyanyian Jepang. Mereka menyatakan bahwa, melantunkan nyanyian Jepang sangat menyenangkan; sehingga secara spontan ketika dimintakan untuk menyanyikan lagu Jepang, mereka dengan sangat antusias langsung menyanyikan sejumlah lagu Jepang. Seluruh lagu tersebut masih teringat cukup kuat, meskipun lagu-lagu atau nyanyian-nyanyian tersebut dipelajari pada enampuluhan tahun silam. Hal ini 
membuktikan betapa kuatnya nyanyian-nyanyian Jepang telah tertancap dalam memori orang Minahasa. Lagu-lagu Jepang dinyanyikan sebagai sarana bernostalgia terhadap berbagai peristiwa yang pernah dialami dalam sejarah perjalanan hidup orang Minahasa, khususnya yang mengalami masa penjajahan Jepang.

Berdasarkan hasil temuan di lapangan, nyanyian-nyanyian yang diajarkan orang Jepang, baik melalui sekolah-sekolah, maupun organisasi-organisasi kemasyarakatan ialah nyanyian-nyanyian yang bernuansa kepahlawanan, romantis, cinta tanah air dan militer. Secara umum, nyanyian-nyanyian tersebut telah berfungsi sebagai sarana propaganda, dan secara khusus nyanyian-nyanyian tersebut telah digunakan untuk memobilisasi masyarakat Indonesia di Minahasa.Menurut (Kurasawa, 1993) nyanyiannyanyian yang dilakukan tersebut ada yang didatangkan dari pustaka Jepang dan ada juga yang digubah di Indonesia dan untuk memudahkan penyebarannya, lagu-lagu tersebut dihimpun dan diterbitkan dalam sebuah booklet yang berjudul "Nyanyian Nippon Boeat Oemoem". Demikian halnya Lagu dari bangsa Jepang yang berpengaruh kuat dan dipelajari orang-orang Indonesia, secara khusus yang ada di suku Minahasa. Bahkan, lagu-lagu berbahasa Jepang masih sering dinyanyikan oleh orang-orang tua di Minahasa yang mengalami masa pendudukan Jepang ini sampai sekarang. Oleh karena itu, Lagu-Lagu Jepang pada masa pendudukan bangsa Jepang di Minahasa tahun 19421945 masih ditemukan dalam memori orang Minahasa yang pernah bersekolah di sekolah Jepang. lirik lagu jika dikaji dengan baik akan membuktikan pertahanan budaya yang pernah dialami oleh sekelompok masyarakat sebagai bagian dari perjalanan hidupnya. Lirik lagu itu dapat juga menyampaikan kesan dan pesan negatif dan positif dari pengalaman hidup yang memang mengalami masa-masa penjajahan yang meninggalkan sejarah kehidupan yang bermakna yang dapat juga menjadi bahan pendidikan dan pengajaran kepada generasi selanjutnya, utamanya pembelajaran bahasa, yang dalam hal ini pengembangan pengajaran bahasa Jepang. Usaha yang perlu dilakukan untuk mengatasi masalah hafalan pada pembelajar menurut Buzan adalah menggunakan metode mnemonik. Mnemonik adalah cara mengelola informasi untuk membuatnya jadi lebih mudah diingat, biasanya dengan menggunakan kode, citra visual atau sajak (kadang-kadang dalam kombinasi. (Lensun, 2016) Secara etimologi, mnemonik berasal dari bahasa Yunani. Kata ini diambil dari dari nama dewa Mnemosyne dalam mitologi Yunani. Mnemosyne berarti berpikir Imajinasi berarti dalam proses pembelajaran bahasa Jepang, pembelajar perlu mengeksplorasi daya imajinatifnya supaya mampu mengingat kosa kata yang dipelajari. masak-masak. Dalam mitologi Yunani, dewa ini (Mnemosyne) memiliki kedudukan setingkat dengan dewa cinta dan kecantikan. Secara terminologis, mnemonik adalah alat pemacu ingatan atau bantuan untuk mengingat sesuatu (memory aid), mnemonik seringkali berbentuk verbal, dan kadang-kadang berbentuk lambang.

Dalam studi ini peneliti menawarkan serpihan solusi untuk ikut mengurai benang kusut yang menimpa dunia pendidikan kita. Dalam tulisan ini penulis akan mengimplementasikan mnemonic dalam proses pembelajaran Bahasa Jepang dengan cakupan kajian bagaimanakah implementasi mnemonik dalam pembelajaran Bahasa 
Jepang melalui media Lagu? Penelitian tentang masa pendudukan Jepang sudah diteliti oleh Ferdy Rorong pada jurnal fakultas bahasa dan seni - kompetensi dengan judul model pengajaran bahasa dan nyanyian nippon pada masa pendudukan. Hasil penelitian yaitu pendudukan Jepang dan dampaknya pada pendidikan khususnya model pengajaran. Untuk menguasai daerah pendudukan seutuhnya, Jepang menerapkan strategi, menarik hati rakyat. Selain itu, mereka mengindoktrinasi masyarakat supaya mendukung kepentingan perang serta mengubah persepsi masyarakat secara keseluruhan bahwa perjuangan Jepang demi kemakmuran bersama. Selama masa pendudukan Jepang, telah terjadi beberapa perubahan dalam pememrintahan dan pendidikan seperti Keresidenan Manado berubah menjadi Manado Syuu. Perubahan status sekolah dilakukan untuk menyesuaikan dengan kemauan penguasa, sekolah dasar pribumi baik yang umum maupun swasta dibuka kembali dan diubah menjadi sekolah rakyat. Dampak pendudukan Jepang memberikan realita yang berbeda. Penguasa menerapkan sistem pengawasan ekonomi secara ketat dengan sanksi pelanggaran yang sangat berat. Pengawasan tersebut diterapkan pada penggunaan dan peredaran sisa-sisa persediaan barang. Pengendalian harga untuk mencegah meningkatnya harga barang. Pengawasan perkebunan teh, kopi, karet, tebu dan sekaligus memonopoli penjualannya. Monopoli tebu dan gula, pemaksaan menanam pohon jarak dan kapas pada lahan pertanian dan perkebunan. Menerapkan sistem ekonomi perang dan sistem autarki (memenuhi kebutuhan daerah sendiri dan menunjang kegiatan perang).

Yang membedakan penelitian ini dengan penelitian sebelumnya adalah pada strategi pembelajaran yang dilakukan dan praktis dapat diimplementasikan dalam pengajaran bahasa Asing.

\section{Metode Penelitian}

Penelitian ini menggunakan metode deskriptif kualitatif dengan pendekatan sejarah melalui teknik analisis isi/content analysis yang meliputi tahap heuristik, kritis, interpretasi(hermeneutik) dan historiografi. Pada tahap heuristic dilakukan pencarian dan penghimpunan data yang ditempuh melalui wawancara, walaupun peneliti mengalami kesulitan karena pelaku atau saksi hidup banyak yang sudah meninggal dunia. Demikian pula, saksi hidup yang masih ada tetap ada kendala disebabkan oleh beberapa hal yaitu faktor usia yang sudah lanjut dan faktor kesehatan yang kurang mendukung sehingga sulit untuk diwawancarai. Faktor lain yang menjadi kendala adalah kurangnya informasi dimana alamat mereka, karena banyak informan yang telah pindah tempat atau alamat.

Data dikumpulkan melalui beberapa proses yang berlapis dan mungkin akan berulang-ulang. Data yang dikumpulkan berupa Lagu berbahasa lokal dan Lagu berbahasa Jepang pada masa pendudukan tahun (1942-1945) berjumlah 31 Lagu yang menjadi sampel adalah tiga buah Lagu dalam lirik bahasa Jepang

Dalam pengumpulan data digunakan metode dan teknik penyediaan data penelitian bahasa yang dikemukakan oleh (MS, 2007), yakni metode simak, metode cakap dan metode introspeksi. Metode simak dilakukan dengan menyimak penggunaan 
bahasa. Penggunaan bahasa yang dimaksudkan menyangkut penggunaan bahasa baik secara lisan maupun tertulis. Secara lisan, yaitu penyadapan penggunaan bahasa saat seseorang atau kelompok menyanyikan Lagu. Secara tertulis, peneliti berhadapan dengan teks (wacana) Lagu.

\section{Hasil dan Pembahasan}

Hasil penelitian ini menunjukkan bahwa (1) pendudukan Nippon di Minahasa dilakukan berdasarkan semangat Nippon untuk memperluas wilayah kekuasaan dan sebagai pembuktian bahwa Nippon adalah bangsa yang mampu menandingi hegemoni Barat. Untuk mendukung tujuan tersebut, di negara-negara yang diduduki Nippon menjalankan taktik kerja rodi, penataan pemerintahan, menjalankan praktik monopoli ekonomi serta pendirian sekolah-sekolah yang tujuannya agar masyarakat mudah dimobilisasi. Sebagai alat propaganda menggunakan sarana nyanyian (2) lirik nyanyian berbahasa Jepang tetap dapat diingat oleh informan, walaupun mereka sudah berusia 80-an tahun dan materi diserap sejak 60-an tahun lalu, hal tersebut disebabkan karena suasana pembelajarannya mengesankan dan dibawakan secara ekspresif dan asosiatif; (3) teridentifikasi bahwa tingkat akurasi pelafalan lirik nyanyian yang dilakukan oleh para informan mengalami kesalahan asistematis dan kesalahan personal; (4) model pembelajaran pada masa pendudukan Nippon dijalankan dengan cara mengoptimalkan aspek-aspek keterampilan berbahasa yang memadukan aspek-aspek keterampilan menyimak (listening) dan mengucapkan (speaking) yang berulang dalam banyak kesempatan (drilling and repetition), serta diikuti oleh praktik menyanyikan dan menggerakkannya (singing and acting), yang menjadi semakin kuat diingat karena diterima pada masa usia muda.

Penelitian ini menemukan formula khas model pembelajaran yang sudah teruji memiliki daya tahan pada diri pembelajar. Melalui penelitian ini dapat direkomendasikan bahwa untuk mencapai pembelajaran yang cepat difahami dan lama diingat maka harus dilaksanakan dengan menciptakan suasana belajar yang mengesankan, berdisiplin, ekspresif dan menerapkan mnemonik yaitu teknik asosiatif dan kata penanda denagn memaksimalkan kompetensi berbicara dan mendengar, pembahasannya sebagai berikut:

\section{A. Mengekspresikan Lagu diikuti Aksi atau Perilaku Tertentu}

Daya ingat seseorang dapat terpicu, apabila seseorang mengalami sentuhansentuhan tertentu, yang mana sentuhan-sentuhan tersebut dapat menimbulkan asosiasi-asosiasi yang berhubungan dengan sesuatu yang diingat. Sentuhansentuhan tersebut dapat berupa pendengaran dan bentuk-bentuk sikap atau perilaku yang dilakukan ketika mempelajari dan mengekspresikan lagu-lagu tersebut. Sebagai contoh, melihat orang bersikap siap dalam upacara bendera, maka orangorang Minahasa teringat ketika mereka mengikuti upacara bendera bersama orang Jepang dan sekaligus mereka langsung dapat mengingat lagu KIMIGAYO yang dinyanyikan ketika upacara tersebut. 
Contoh lain juga, ketika peneliti mencoba bertanya tentang pengalaman para informan saat menyanyikan lagu-lagu, para informan langsung menyanyikan lagulagu yang pernah dan dilakukan di masa lalu, akan tetapi juga mereka langsung melakukan gerakan-gerakan atau tindakan-tindakan yang dilakukan, ketika mereka menyanyikan lagu-lagu tersebut di masa lalu. Sebagai contoh, terdapat lagu-lagu yang lucu, dan ketika mereka menyanyikan lagu-lagu tersebut, mereka langsung bergerak dan menirukan gerakan-gerakan dianggap pada waktu itu sebagai hal-hal yang lucu.

Pada beberapa informan, ketika diminta menyanyikan lagu-lagu yang pernah dinyanyikan, para informan langsung berdiri dan melakukan gerakan-gerakan seperti berjalan dalam barisan sambil menyanyi. Sebagian juga melakukan kegiatan bernyanyi sambil meniru gerakan-gerakan seperti ketika mereka bekerja. Berikut penuturan yang disampaikan informan sehubungan dengan perilaku yang dilakukan pada waktu mereka menyanyikan lagu-lagu Jepang.

Dalam rangka pembinaan kesiswaan, Jepang mewajibkan bagi setiap murid sekolah untuk rutin melakukan beberapa aktivitas berikut ini: (1) Menyanyikan lagi kebangsaan Jepang, KIMIGAYO setiap pagi; (2) Mengibarkan bendera Jepang, Hinomura dan menghormat Kaisar Jepang, Tenno Heika setiap pagi; (3) setiap pagi mereka juga harus melakukan Dai Toa, bersumpah setia kepada cita-cita Asia Raya; (4) Setiap pagi mereka juga diwajibkan melakukan Taiso, senam Jepang; (5) Melakukan latihan-latihan fisik dan militer; (7) Menjadikan bahasa Indonesia sebagai pengantar dalam pendidikan. Bahasa Jepang menjadi bahasa yang juga wajib diajarkan. Semua Lagu yang dilakukan da diikutsertakan dengan aktifitas atau perilaku seperti dipaparkan di atas, memberi kesan tersendiri dan sangat mempengaruhi para informan untuk tetap mengingat lagu-lagu yang mereka nyanyikan.

\section{B. Belajar dengan Simbol, Ilustrasi, Imajinasi, Asosiasi, dan Kesan}

Proses mengingat akan sangat ditunjang juga apabila apa yang ingin diingat tersebut disampaikan dengan simbol yang sangat berkesan atau lukisan imajinasi tertentu yang mengetarkan hati dan perasaan. Sebagai contoh lagu SHIRO JIN berikut.

Shiro jin ni akaku, Shiroo maru agete au utsukushi, Nippon no hata wa

白人，白人に赤く白丸上げて会う美しい 日本の旗は

Terjemahan bebas

Orang kulit putih dengan wajah kemerahan itulah orang Jepang, Benderanya adalah bendera putih dengan lingkaran merah yang ada ditengah-tengahnya.

Dengan menggunakan simbol warna dan bentuk, maka orang akan dapat mengingat bendera Jepang dan secara tidak langsung akan mengakui kehebatan bangsa jepang. Proses mengingat kembali lirik-lirik lagu oleh orang-orang Minahasa juga disebabkan oleh beberapa hal antara lain terdapatnya sentuhansentuhan yang dapat memancing orang-orang Minahasa langsung berasosiasi 
terhadap yang terjadi di masa lalu, terlebih konteks ketika mereka mempelajari lagu atau mengekspresikan lagu-lagu.

Hal ini dapat dibandingkan seperti dengan yang dikatakan (Buzan, 2006), terlebih menyangkut teknik memori dengan menggunakan asosiasi, gambaran, dan lokasi. Sesuatu mudah diingat apabila sesuatu tersebut dilakukan dalam konteks tertentu yang berkesan. Sesuatu yang berkesan sangat mudah diingat di masa datang, apalagi terdapat hal-hal yang dapat memancing asosiasi-asosiasi muncul (Lolong, 1999; Maru, Nur, \& Lengkoan, 2020).

Sangat jelas terlihat, bahwa setiap saat para informan menyanyikan lagu-lagu Jepang, mereka selalu mengingat kejadian yang terjadi saat itu. Kejadian-kejadian tersebut sangat berkesan, baik yang dirangsang oleh pengalaman-pengalaman estetis, juga karena ketika mereka menyanyikan lagu-lagu tersebut terdapat situasi yang menggetarkan hati, perasaan takut, kelelahan, lapar, intimidasi, perlakuan kasar dari pihak Jepang dalam proses indoktrinisasi, dll. Diakui, bahwa selain alasan rangsangan dan kesan serta sikap atau perilaku, kemampuan menghafal seseorang yang berbeda-beda juga cukup mempengaruhi daya ingat seseorang. Bandingkan dengan tujuh jenis kecerdasan seperti dikatakan (Sobur, 2006; Syafrudin, Edwita, \& Sarkadi, 2018), di mana ia mengatakan, bahwa manusia memiliki tujuh jenis kecerdasan dan ada di antaranya yang dimiliki seseorang secara menonjol. Salah satu kecerdasan yang berhubungan dengan yang dikatakan tersebut adalah kecerdasan linguistik. Dari beberapa informan yang sempat ditemui, fenomena ini sangat jelas terlihat.

Kesan dalam mempelajari dan melakukan sangatlah mempengaruhi proses mengingat dan proses lupa akan sesuatu. Hal ini sejalan dengan pandangan para psikolog. Kalangan psikolog mengatakan, bahwa ada 3 unsur dalam perbuatan ingatan yaitu: menerima kesan-kesan, menyimpan dan mereproduksikan. Dengan adanya kemampuan untuk mengingat pada manusia ini berarti ada suatu indikasi bahwa manusia mampu untuk menyimpan dan menimbulkan kembali dari sesuatu yang pernah dialami. Namun tidak berarti bahwa semua yang pernah dialami itu akan tetap tinggal seluruhnya dalam ingatannya, oleh karena ada berbagai faktor yang mempengaruhi daya kerja ingatan, antara lain kondisi jasmani misalnya kelelahan, sakit dan kurang tidur, serta faktor usia.

\section{Belajar Dengan Mengulang-Ulang Sesuatu yang Sama}

Hal lain yang juga sangat mempengaruhi sesuatu dapat bertahan dalam ingatan adalah apabila hal tersebut dilakukan secara berulang-ulang. Rata-rata lagulagu yang dipelajari dan dilakukan secara berulang-ulang akan sangat melekat dalam ingatan. Orang Minahasa yang mengingat lagu-lagu Jepang dalam hal ini para informan mengakui, bahwa mereka masih dapat mengingat lagu-lagu termasuk lirik dalam lagu tersebut karena lagu-lagu tersebut sudah menjadi santapan harian dan dilakukan secara berulang-ulang. Menurut para informan, apabila mereka menyanyikan lagu-lagu tersebut, bukan saja lirik yang dapat diingat, akan tetapi suasana, situasi serta hal-hal yang terjadi ketika lagu tersebut dinyanyikan. Sangat 
jelas, bahwa kata-kata yang ada dalam lagu masih jauh lebih bertahan dalam ingatan, dari pada kata-kata yang bukan berada dalam lagu seperti puisi atau dalam tulisan-tulisan lainnya.

Dengan adanya kemampuan untuk mengingat pada manusia ini berarti ada suatu indikasi bahwa manusia mampu untuk menyimpan dan menimbulkan kembali dari sesuatu yang pernah dialami. Namun, tidak berarti bahwa semua yang pernah dialami itu akan tetap tinggal seluruhnya dalam ingatannya, oleh karena ada berbagai faktor yang mempengaruhi daya kerja ingatan, antara lain kondisi jasmani misalnya kelelahan, sakit dan kurang tidur, serta faktor usia. Selain itu, faktor emosi, di mana seseorang akan mengingat sesuatu lebih baik, apabila peristiwaperistiwa itu menyentuh perasaan-perasaan. Demikian para informan yang pernah menyanyikan lagu-lagu Jepang, ada yang masih dapat mengingat secara utuh, akan tetapi ada yang mulai melupakan sedikit bagian dari lagu tersebut. Akan tetapi, apabila terdapat rangsangan dari rekan-rekan informan lainnya, maka orang tersebut segera dapat mengingat kembali lagu tersebut. Informan-informan tersebut umumnya yang telah berusia sangat lanjut.

Pengajaran lagu dilakukan setiap hari pada waktu memulai pelajaran sehingga menimbulkan semangat untuk belajar, walaupun lagu yang diajarkan dalam bahasa Jepang dan tidak ada terjemahannya. Karena lagu yang dipelajari sangat menyenangkan akhirnya lagu tersebut dinyanyikan berulang-ulang, demikian proses mengingat semakin kuat. Para penyanyi lagu-lagu Jepang juga mengalami pengalaman seperti itu, yakni pada tahap pertama mereka hanya mau menikmati lagu-lagu yang diperkenalkan orang Jepang kepada mereka. Hal ini sangat mungkin terjadi mengingat seperti yang telah disampaikan di depan, bahwa orang Minahasa dikenal sebagai masyarakat bernyanyi. Apabila hati orang Minahasa disentuh dengan lagu, maka hati orang Minahasa akan lebih mudah terbuka dan menerima sesuatu yang diperkenalkan kepada mereka. Pada tahap berikutnya setelah mereka senang dan melakukan atau mengekspresikan Lagu-Lagu yang diperkenalkan kepada mereka, mereka pun akan berusaha untuk memahami isi dari lagu tersebut, minimal memahami isi atau pesan yang terdapat dalam lagu, khususnya dalam liriknya. Mungkin mereka tidak mencapai tahap analisis lagu tersebut, akan tetapi minimal misi Jepang telah sampai dan akan disenangi seiring dengan disenanginya lagu tersebut.

\section{Kesimpulan}

Dari beberapa hal yang dikemukakan di atas dapat ditarik kesimpulan bahwa penerapan mnemonik dalam pembelajaran bahasa Jepang melalui media lagu terbukti sangat efektif, karena masih dapat bertahan dalam ingatan orang Minahasa hingga saat ini, kendati kini para penyanyi tersebut telah berusia lanjut. Metode mnemonik dengan teknik asosiasi dan kata penanda. Situasi yang alami dalam berlatih, ada kecenderungan mempunyai pengaruh yang signifikan dalam proses pencapaian belajar bahasa. Teridentifikasi 5 macam teknik dari metode mnemonik 
yang dipakai para pembelajar bahasa Jepang zaman pendudukan Jepang 1942-1945 yaitu: Mengekspresikan Lagu diikuti Aksi atau Perilaku Tertentu, Belajar dengan Simbol, Ilustrasi, Imajinasi, Asosiasi, dan Kesan, Belajar Dengan Mengulang-Ulang Sesuatu yang Sama, Menghafal kata-kata yang Dekat dengan Tubuh Kita dan KataKata yang setiap Hari digunakan, Belajar dengan Paksaan, Intimidasi, dan Perasaan Takut

Aspek-aspek keterampilan berbahasa yang berfokus pada mendengar dan berbicara dengan penerapan berulang-ulang pada berbagai kesempatan termasuk pembelajaran Lagu yang selain berulang-ulang diikuti dengan gerakan kinestetik dan dimulai pada usia muda menghasilkan ingatan "memori" yang teruji memiliki daya tahan mengingat dalam jangka waktu yang lama. 


\section{BIBLIOGRAFI}

Amstrong, Thomas. 2002. Setiap Anak Cerdas. Jakarta : PT Gramedia Pustaka Utama. Effendi, Google Scholar

Agus. 2005. Revolusi Kecerdasan Abad 21. Bandung : Alfabeta. Google Scholar

Buzan, Tony. (2006). Master your memory. Pearson Education. Google Scholar

Huda, Miftahul. (2017). Model-model pengajaran dan pembelajaran: Isu-isu metodis dan paradigmatis. Google Scholar

Krashen, Stephen D. (1984). Second Language Acquisition and Second Language Learning. London: Pergamon Press. Google Scholar

Kurasawa, Aiko. (1993). Mobilisasi dan kontrol: studi tentang perubahan sosial di pedesaan Jawa, 1942-1945. Diterbitkan atas kerja sama Yayasan Karti Sarana dengan Penerbit PT Gramedia. Google Scholar

Lensun, Sherly Ferro. (2016). Peningkatan Penguasaan Kanji dengan Met Ode Nemonik melalui Multimedia. Bahtera: Jurnal Pendidikan Bahasa Dan Sastra, 15(1), 107117. Google Scholar

Lolong, Hans. A. (1999). Tahun Dai Nippon di Minahasa (1942-1945). Manado: Yayasan Bhakti Mapalus Sejahtera.

Maru, Mister Gidion, Nur, Sahril, \& Lengkoan, Fergina. (2020). Applying Video for Writing Descriptive Text in Senior High School in the Covid-19 Pandemic Transition. International Journal of Language Education, 4(3). Google Scholar

MS, Mahsun. (2007). Metode Penelitian Bahasa. Jakarta: PT Raja Grafindo Persada. Google Scholar

Rorong, ferdy . 2013 Latar Kesejarahan Pada Masa Pendudukan Jepang Di Minahasa Dalam Hubungan Dengan Bertahannya Bahasa Dalam Memori Vol 1, No 1 (2013): Artikel Ilmiah Dosenurnal Fakultas Bahasa dan Seni-Kompetensi

Rumengan, Perry. (2007). Musik vokal etnik Minahasa:: Kontinuitas dan perubahan dalam struktur dan fungsi. Universitas Gadjah Mada. Google Scholar

Sobur, Alex. (2006). Semiotika Komunikasi. Bandung: Penerbit PT Remaja. Google Scholar

Syafrudin, Ulwan, Edwita, Edwita, \& Sarkadi, Sarkadi. (2018). Pembelajaran Unik Pada Anak Yang Memiliki Kecerdasan Visual Spasial Yang Mengalami Kesulitan Belajar. Elementary: Jurnal Ilmiah Pendidikan Dasar, 4(2), 149-160. Google Scholar 
Copyright holder :

Susanti Aror (2021)

First publication right :

Jurnal Syntax Literate

This article is licensed under:

(c) $\bigoplus_{\mathrm{EY}} \ominus_{\mathrm{ND}}$ 